suggestions covering five points, including the proposal for a Malaria Prevention Act to be passed by Parliament, might receive fuller appreciation if the author gave some figures stressing the gravity (or lack of it) of the situation.

Over the past 10 years the number of deaths reported in the United Kingdom as due to malaria was as follows: 1963,$4 ; 1969,9 ; 1970$, $5 ; 1971,9 ; 1972,7 ; 1973,5 ; 1974,2 ; 1975,5$; 1976,$3 ; 1977,7$.

During the first nine months of 1978 there were eight deaths related to 1533 cases of malaria imported into this country; of these, 201 cases were due to Plasmodium falciparum. The mean fatality rate of $P$ falciparum malaria notified in this country in the past decade is $4 \%$. This should certainly cause much concern since it reflects the delays in the diagnosis of the disease and also the shortcomings of prompt and adequate treatment of severe malaria.

No one will deny that these 64 deaths over the stated period are most regrettable and call for greater awareness of the danger of contracting malaria abroad and of the severity of the imported disease. The travel agencies in particular must recognise their special responsibility in this respect. The medical profession has been regularly informed of the problem by the Department of Health and Social Security but such educational activity could well be increased and widened. The World Health Organisation published recently a comprehensive document on malaria risk for international travellers and the ways to avoid it. This paper is obtainable from the WHO headquarters in Geneva on request. ${ }^{1}$

Whether the heroic measures outlined by Dr Hall are called for is a moot point, especially when we remember that motor accidents alone cause in England and Wales some 6000 7000 deaths every year, many of which are preventable by legislative or educational measures. I for one believe that the compulsory procedures advocated by $\mathrm{Dr}$ Hall, while understandable, are not necessary and some of them may be counterproductive or open to abuse and litigation. On the other hand much more effort should be made by the authorities and by the professional organisations to inform and advise everyone concerned.

World Health Organisation,

L J BRUCE-ChWATt

${ }^{1}$ World Health Organisation, Information on Malaria Risk for International Travellers. Reprinted from WHO Weekly Epidemiological Record. Geneva,

\section{African travel}

SIR,-We would like to comment on Dr S G Barber's preparations for a trans-Saharan expedition (5 August, p 404) and suggest some amendments.

Firstly, his choice of antibiotics lacks essential specificity. Typhoid fever must always remain a risk to the Saharan traveller despite immunisation. Even the acetone-killed vaccine does not provide complete immunity. It is therefore important to carry specific chemotherapy for the treatment of Salmonella typh $i$ infection. Full courses of chloramphenicol or co-trimoxazole should guarantee a complete cure, whereas ampicillin ensures only an $80 \%$ cure rate. ${ }^{1}$ Any trans-Saharan party should be aware that meningococcal meningitis epidemics are common and widespread in the savanna region of Mali, Upper Volta, Niger, and Nigeria in February, March, and April. It would therefore be wise for any traveller to receive prophylactic immunisation against the meningococcus before leaving Europe if travelling in the dry season. It would also be prudent to carry effective chemotherapy against a meningococcal infection. Ampicillin is not the drug of choice, whereas chloramphenicol has been shown to be as effective as benzylpenicillin in the treatment of meningococcal meningitis. ${ }^{2}$

Chloroquine is included only in tablet form. Vomiting and prostration may complicate acute malaria and the inclusion of injectable chloroquine would seem a sensible precaution.

If the party has female members clotrimazole vaginal tablets and cream would be indispensable. Personal hygiene may be difficult and hence vaginal candidiasis all the more likely, particularly if the lady is consuming $\mathrm{Dr}$ Barber's contraceptive pills.

In the unfortunate event of having to manage an unconscious fellow traveller no doctor should be without an airway. Another useful item is a pair of Spencer Wells forceps should the doctor have to attempt to deal with a torn major artery.

Finally, having included local anaesthetic, it is a pity that Dr Barber does not advocate its use in treating the excruciating pain following a scorpion bite.

D L CHILD

V M CHILD

Wusasa Hospital

C J TARRANT

Wusasa PA

' Chan, A C H, and Mak, M H H, Tropical Doctor, 1976, 6, 53.
Whittle, H C, al, British Medical fournal, 1973, 2 ,

\section{Childhood epilepsy}

SIR,-I fear that compression may have led Dr D P Addy in his article on childhood epilepsy (16 September, $p$ 811) to give advice on the dosage of paraldehyde which could be excessive. The dosage of $1 \mathrm{ml}$ per year of age may be well enough in the first two or three years of life, when admittedly most of these problems arise, but in an older child it could be excessive. On his own recommendation of $0 \cdot 15 \mathrm{ml} / \mathrm{kg}$ body weight this would give a $23-\mathrm{kg}$ 7 -year-old child a dosage of about $3.5 \mathrm{ml}$. The dosage of $1 \mathrm{ml}$ per year would give him $7 \mathrm{ml}$, while a 12-year-old would receive $12 \mathrm{ml}$, a dosage considerably in excess of the usual adult dosage.

ROBERT A SHANKS

Royal Hospital for Sick Children,

Glasgow

${ }^{*} *$ We sent a copy of this letter to Dr Addy, whose reply is printed below.-ED, $B M F$.

SIR,-Dr Shanks is, of course, right in pointing out that the traditional $1 \mathrm{ml}$ per year dose of paraldehyde is only really applicable to young children, who are the great majority of children with status epilepticus. The maximum dose should be $8 \mathrm{ml}(4 \mathrm{ml}$ in two different sites), and in older children it would be better to stick to $0 \cdot 15 \mathrm{ml} / \mathrm{kg}$. Paraldehyde is; however, a relatively safe drug and the dose of $1 \mathrm{ml}$ per year has been quoted in several leading paediatric texts for very many years without apparent dire consequences. Perhaps doctors in practice have more common sense than they are sometimes given credit for-I presume, for instance, that no one is going to employ all the measures listed in my article under status epilepticus at once but that they will be employed sequentially in resistant cases.

I am grateful, however, to Dr Shanks for pointing out the limitations of the $1 \mathrm{ml}$ per year aide-mémoire.

D P ADDY

Dudley Road Hospital,

Birmingham

\section{Paediatric anaesthesia}

SIR,-Your leading article (9 September, $p$ 717) on this subject illustrates an undesirable side effect of the policies and plans which so beset the hospital services. Why is it "clearly ... correct" to concentrate paediatric surgery in large centres? Are we to understand, for example, that infant craniotomies should not be performed in neurosurgical units or cleft lips repaired in plastic units and that orthopaedics, ear, nose, and throat, and eye work outside these paediatric centres should be confined to adult patients?

It is not disputed that it is vital to keep and continuously improve our children's hospitals of international standing, but the staff working in them should strive to avoid the degeneration from centres of excellence to centres of arrogance. It is one thing to have a few large hospitals dealing with the surgery and general management of life-threatening congenital abnormalities, quite another to argue that these are the only fit places to deal with the mass of more ordinary but interesting and varied clinical material that forms the bulk of children's work.

If this nonsense goes on small children's hospitals and the children's wards in district hospitals will get reorganised, reallocated, RAWPed up, normalised, rephased, or just plain closed. This will be to the detriment of all-parents, children, nurses, technicians, radiographers, physiotherapists, doctors, etcexcept presumably the hierarchy who make the decisions but don't actually deal with patients and their paediatric advisers who appear to regard themselves as the only people fit to deal with children.

J V I Young

St Mark's Hospital

London EC

\section{False-negative hypoglycaemic} screening test for patients in coma

SIR,-A 42-year-old known diabetic patient was brought to the hospital emergency department recently having been found cold, clammy, and: unconscious. A screening blood sugar estimation, performed by the nursing staff using the Reflomat method (Boehringer Corporation Ltd), showed an apparent blood glucose level of $4.0 \mathrm{mmol} / 1$ $(72 \mathrm{mg} / 100 \mathrm{ml})$. In the absence of other discernable causes for his condition a further blood sample was taken for subsequent laboratory analysis and $40 \mathrm{ml}$ of $50 \%$ dextrose was given intravenously. Consciousness was restored and the patient then gave a history of taking insulin without food. Analysis of the fluoride blood specimen by the Catalinks (Ames Co) glucose oxidase method showed that the true glucose level had been $0.6 \mathrm{mmol} / 1$ $(10.8 \mathrm{mg} / 100 \mathrm{ml}$ ) 
Further investigation has shown that the incorrect Reflomat result may have resulted from inserting the Reflomat strip into the machine upside down, which can give spurious readings up to $4.0 \mathrm{mmol} / \mathrm{l}$. Incorrect insertion of the strip is, of course, more likely when testing for hypoglycaemia since the test surface fails to show significant colour change in this situation. This problem does not appear to be significant with the more recently available Reflotest-Hypoglycémie strips, though false results may occur. if either of the strips is not fully inserted into the machine.

Although all laboratory results should be interpreted in the context of the clinical findings, we should like to alert your readers to this potential cause of error and suggest that the manufacturers alter the colour of the blank reverse side of the strip to obviate this risk.

We should like to emphasise, however, that provided that the instructions are followed and the strips used correctly the Reflomat method has proved reproducible, accurate, and reliable.

J H REYNOLDS

$S$ G BARBER

J H SMITH

General Hospital

A D WRIGHT.

Birmingham

***The authors sent a copy of this letter to the Boehringer Corporation, whose reply is printed below.-ED, $B M F$.

SIR,-The Reflomat and Reflotest system was designed to be simple and reliable to operate both in the laboratory and in the hands of the appropriate staff throughout the hospital, and thus Boehringer Mannheim and the Boehringer Corporation (London) regret that this mishap has occurred.

We have not been able to reproduce the results reported since using the standard Reflotest strip upside down in the instrument gives a low (virtually zero) reading on the scale and not a higher result as indicated in the letter. Thus inserting the strip upside down cannot lead to overlooking a possible hypoglycaemia. The only way that we feel this result could have occurred is by inadvertently reading a Reflotest-Hypoglycémie strip by means of the normal black Reflotest scale instead of the correct Reflotest-Hypoglycémie scale, which is coloured grey. Our tests showed that if this occurred with a sample containing $0.6 \mathrm{mmol} / \mathrm{l}$ a result of $4.2 \mathrm{mmol} / 1(75.7 \mathrm{mg} /$ $100 \mathrm{ml}$ ) could be erroneously obtained.

At present normal Reflotest scales are coloured black and Reflotest-Hypoglycémie scales are grey with a corresponding grey marking on the Reflotest-Hypoglycémie strips. Reflotest-Glucose strips do not at present have any colouring on the reverse side. While we are sure that even the best possible system cannot exclude human error, we are always eager to improve the safety and quality of our products and therefore take this letter seriously. Accordingly, future batches will be redesigned so that the labels of both types of strip are different and the possibility of producing a coloured reverse side to the Reflotest-Glucose strip will be investigated.

P ProetzSCH H WENDEL Scientific ManagementRapid Diagnostics
Bantinger Manneim
Erythema chronicum migrans in Britain

SIR,-Further to your recent leading article "Ticks, tourists, and encephalitis" (26 August, p 587), we would like to report six cases of erythema chronicum - migrans (ECM) seen in that area of East Anglia served by the Cambridge department of dermatology in the past three years. ECM is a clinically distinctive variant of the rather heterogeneous group of annular erythemas but its aetiology remains obscure, although it is generally considered to be due to a tick-borne non-bacterial infectious agent. Until recently cases of ECM originating outside Scandinavia and certain other parts of Europe were rare and most European reports incriminate the tick Ixodes ricinus as vector.

All the patients, four of whom were male adults, gave similar histories. An irritable primary reaction would be followed by the appearance of, an erythematous, slightly indurated ring which slowly extended with central clearing over successive months until they sought treatment. The width of the erythematous band at the time of examination was approximately $2 \mathrm{~cm}$ and the diameter of the largest of the rings was about $75 \mathrm{~cm}$ Clearance occurred within a féw days of starting a course of oral penicillin. Little or no systemic upset was reported by our patients, although one had a penicillin reaction. Routine blood counts were normal and no elevation of Weil-Felix titres was detected. Biopsy was performed on one lesion and a mild perivascular lymphocytic infiltrate was seen in the mid-dermis

Rickettsiae, spirochaetes, and viruses have all at times been incriminated as infecting organisms and perhaps the speed of resolution following treatment with penicillin, erythromycin, or tetracycline might favour a rickettsia infection.

While most of our patients felt they had been bitten by an insect, none considered it had been a tick. Four cases came from the region of the Thetford Forest, where ticks reputedly exist, and one patient was bitten by something while walking in the forest Another case has been reported from south east Scotland. ${ }^{1}$

David GoldiN

Kent and Canterbury Hospital

Kent and Canterbury

H ChampioN ARTHUR ROOK

Addenbrooke's Hospital, S O B ROBERT

' Obasi, O E, British fournal of Dermatology, 1977, 97,

\section{Ingrowing toenails in infancy}

SIR,-I agree with Mr F B Bailie and Mr D M Evans (9 September, p 737) that ingrowing toenail certainly occurs in infants but is uncommon. In my experience the usual cause in an infant is unduly prominent skin at the extreme tip of the big toe forming an anterior nail fold which encourages ingrowing and prevents the free end of the big toe nail growing normally; the condition may sometimes be genetically determined. I wonder, in fact, whether this was the cause in the first of the cases reported by $\mathbf{M r}$ Bailie and $\mathrm{Mr}$ Evans.
The figure shown illustrates the right big toe nail ingrowing and the anterior nail fold in a boy aged 9 months. The condition was asymptomatic until he started wearing shoes around the age of 18 months, when the lateral and medial nail folds became inflamed. However, he is now 2 years 8 months old and, although the nail remains ingrown, he is not troubled at all because he wears wide-toed shoes. In addition, over the past six months or

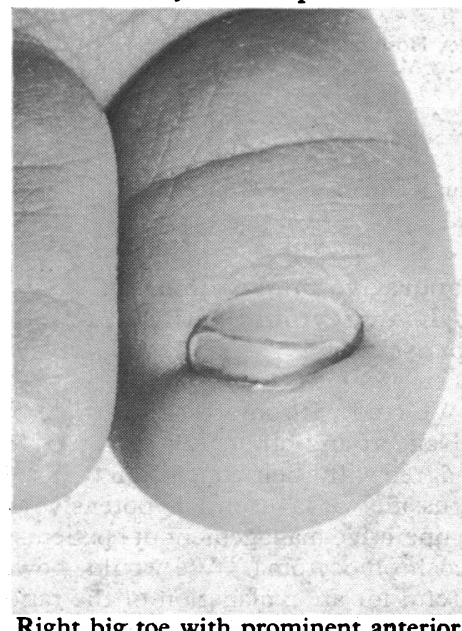

ight big toe with prominent anterior nail fold in male infant aged 9 months.

so the skin at the toe tip has ceased to overhang and looks normal. In this particular infant the big toe nail has never required trimming because it grows very slowly. The left big toe and nail are normal. The boy's father has had long-standing trouble with an ingrowing big toe nail which has recurred despite avulsion of the toe nail on two occasions in his teens.

As a general rule, surgery should be avoided both because of the likelihood of recurrence and because some cases do improve spontaneously. Pressure trauma to the skin around the nail must be minimised and topical antiseptics/antibiotics may be required for paronychia.

Royal Liverpool Children's Hospital,

JULIAN VeRBOV

Liverpoo

\section{Health of King Henry VII}

SIR,-May we acknowledge the reply of.Dr R J Hetherington (30 September, p 956) which, in part, indicates the reports in The Complete Peerage of the hearsay evidence of an illegitimate son, Henry Carey, not recognised by the King during his lifetime? Notwithstanding the retrospective reports of the hearsay evidence, one illegitimate birth, where fathering, putative or not, is attributed to the King, does not significantly affect the total of surviving births (two females and two males after multiple partners) over the long period of 38 years (2 September, p 700). Against which matters of undoubted fact we may now balance and weigh by other criteria the evidence of a contemporary, independent informant who secretly communicates for posterity at the risk of his life on dangerous matters without possibility of any benefit or reward during his lifetime. ${ }^{1}$ May we offer an opinion that Hans Holbein, the informant, appears to have made his point on the underlying "genetic impediment" of the King? The artist's comment is relevant.

We hope that Dr.Hetherington will consider 